LOCKUEED MATTU/7

ENVIRONMENTAL

RESTORATION

PROGRAM

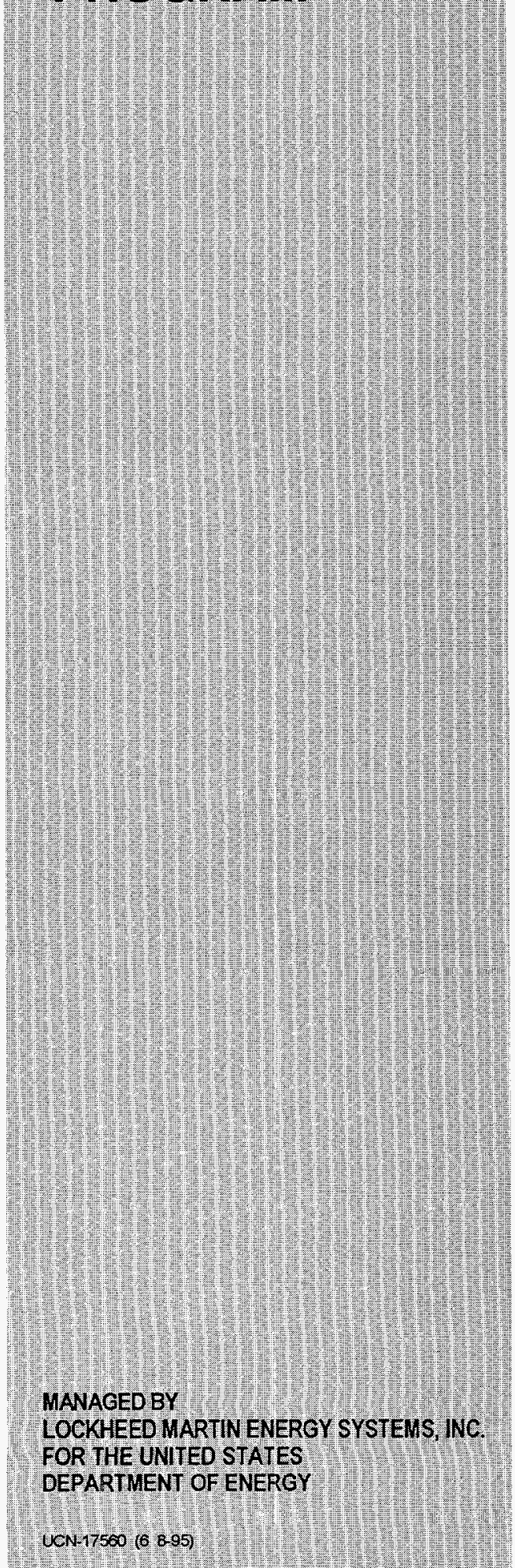

ORNL/ER-410

\title{
Baseline Monitoring and Simulated Liquid Release Test Report for Tank W-9, Oak Ridge National Laboratory, Oak Ridge, Tennessee
}

\author{
RECEVED \\ AU6 281997 \\ OSTI
}



This document has been approved by the ORNL Technical Information Office for release to the public. Date: $8 / 6 / 97$

ENERGY SYSTEMS

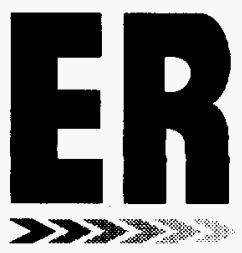


Vista Research, Inc.

contributed to the preparation of this document and should not be considered an eligible contractor for its review. 
ORNL/ER-410

\section{Baseline Monitoring and Simulated Liquid \\ Release Test Report for Tank W-9, Oak Ridge National Laboratory, Oak Ridge, Tennessee}

Date Issued-August 1997

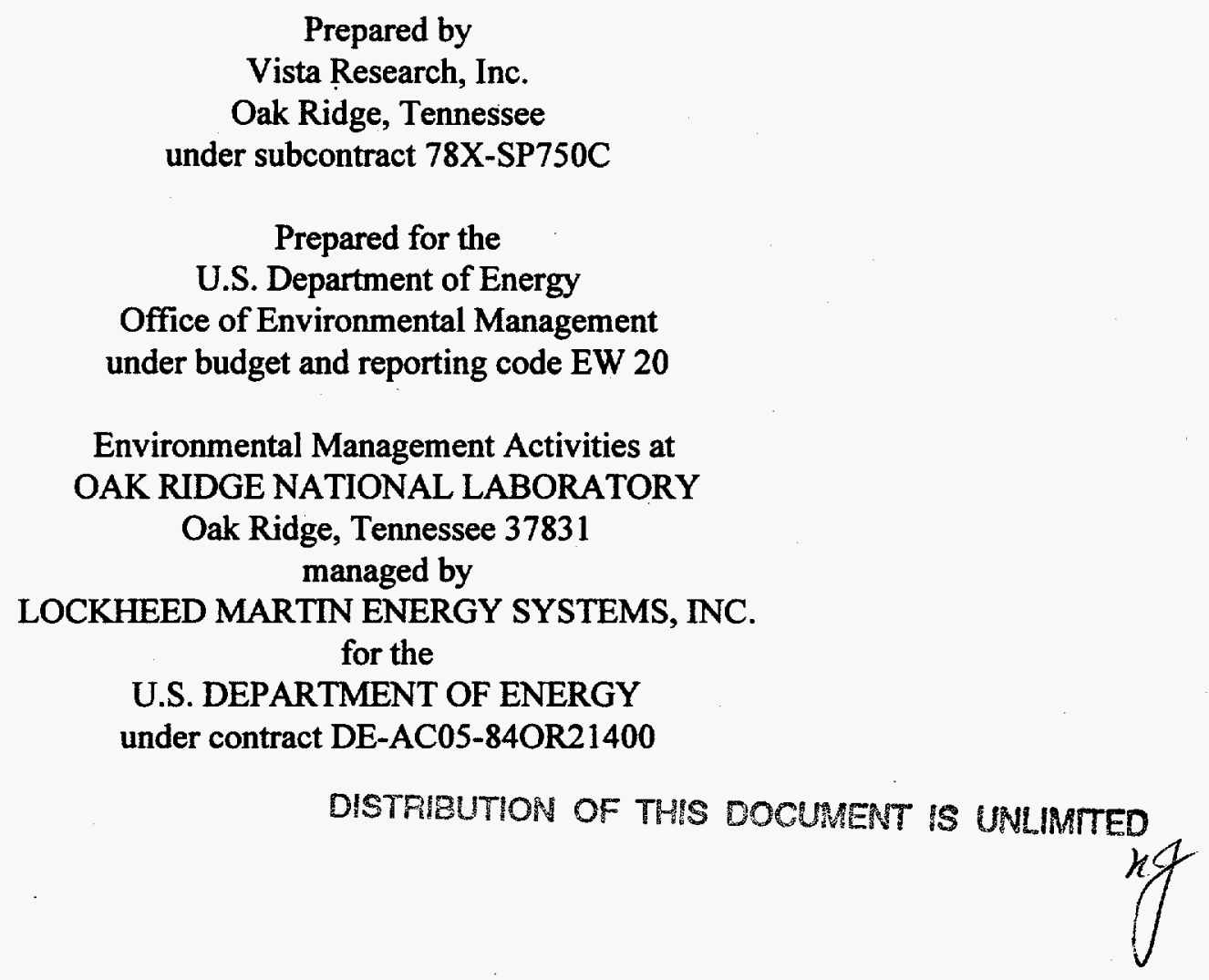




\section{DISCLAMMIXR}

Portions of this document may be illegible in electronic image products. Images are produced from the bert available original docoment. 


\section{PREFACE}

This report, Baseline Monitoring and Simulated Liquid Release Test Report for Tank W-9, Oak Ridge National Laboratory, Oak Ridge, Tennessee (ORNL/ER-410), was developed under Work Breakdown Structure 6.1.01.41.05.05.05 (Activity Data Sheet 3301, "WAG 1"). This document provides the Environmental Restoration Program with the baseline dry well conductivity monitoring data and simulated liquid release tests results to support the use of Gunite and Associated Tank (GAAT) W-9 as a temporary consolidation tank during waste removal operations. Information provided in this report forms part of the technical basis for criticality safety, systems safety, engineering design and waste management as they apply to the GAAT treatability study and waste removal actions.

\section{DISCLAIMER}

This report was prepared as an account of work sponsored by an agency of the United States Government. Neither the United States Government nor any agency thereof, not any of their employees, makes any warranty, express or implied, or assumes any legal liability or responsibility for the accuracy, completeness, or usefulness of any information, apparatus, product, or process disclosed, or represents that its use would not infringe privately owned rights. Reference herein to any specific commercial product, process, or service by trade name, trademark, manufacturer, or otherwise does not necessarily constitute or imply its endorsement, recommendation, or favoring by the United States Government or any agency thereof. The views and opinions of authors expressed herein do not necessarily state or reflect those of the United States Government or any agency thereof. 


\section{CONTENTS}



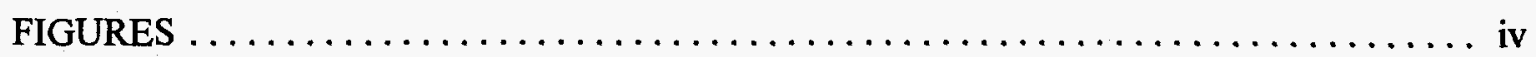
ABBREVIATIONS $\ldots \ldots \ldots \ldots \ldots \ldots \ldots \ldots \ldots \ldots \ldots \ldots \ldots \ldots \ldots \ldots \ldots \ldots, \mathbf{v}$

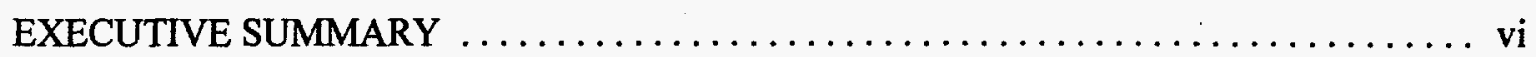

1. INTRODUCTION $\ldots \ldots \ldots \ldots \ldots \ldots \ldots \ldots \ldots \ldots \ldots \ldots \ldots \ldots \ldots \ldots \ldots \ldots \ldots$

2. SET-UP FOR CONDUCTIVITY MONITORING AND SLR TESTING IN TANK W-9 . 2

3. RESULTS OF BASELINE CONDUCTIVITY MONITORING IN DRY WELL DW-9 . . 5

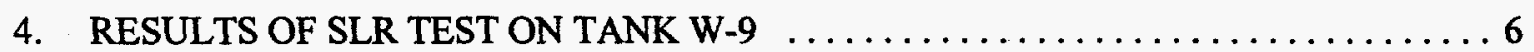

5. MONITORING PLAN FOR W-9 CONSOLIDATION TANK $\ldots \ldots \ldots \ldots \ldots \ldots$

6. CONCLUSIONS AND RECOMMENDATIONS $\ldots \ldots \ldots \ldots \ldots \ldots \ldots \ldots \ldots, \ldots$

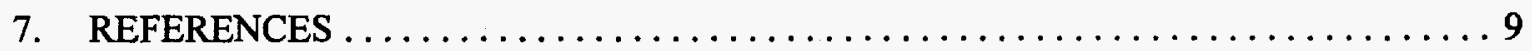




\section{FIGURES}

1 Plan view of NTF and STF showing the location of the GAAT, including Tank W-9,

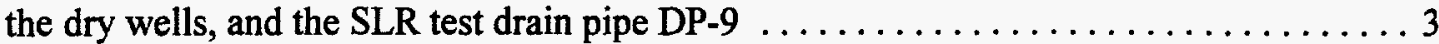

2 Cut-away view of Tank W-9 showing the tank, tank pad, dry well, and drain pipe for the SLR test

3 Cross section of DW-9 showing the location of the PVC screen and riser, the conductivity sensor, and the level of water in the dry well $\ldots \ldots \ldots \ldots \ldots \ldots \ldots$

4 Plot of DW-9 conductivity and ORNL cumulative rainfall data from May 15 through

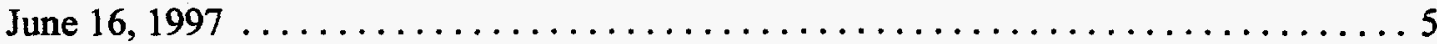

5 Plot of SLR test on Tank W-9 (12:30 p.m. on June 16 through 8:30 a.m. June 20, 1997), before, during, and after the SLR test period, showing conductivity data from DW-9 and cumulative rainfall data (June 13 to July 2, 1997) 


\section{ABBREVIATIONS}

GAAT Gunite and Associated Tanks

NTF North Tank Farm

ORNL Oak Ridge National Laboratory

PVC polyvinyl chloride

SLR simulated liquid release

STF South Tank Farm 


\section{EXECUTIVE SUMMARY}

A treatability study and waste removal program are being implemented for the Gunite and Associated Tanks (GAAT) Operable Unit in the North and South Tank Farms at Oak Ridge National Laboratory. It is planned that Tank W-9, located in the South Tank Farm, will be used to consolidate the liquids and sludge removed from the other GAAT tanks before the transfer of these materials elsewhere for treatment and storage.

Prior work has shown that Tank W-9 is structurally sound and leak free. To detect any releases that might occur from W-9 during the study and waste removal program, an external release-detection monitoring program has been developed for this tank. The external monitoring method relies on measuring the electrical conductivity of the water flowing at the bottom of the dry well adjacent to W-9.

This report describes the baseline conductivity conditions in the dry well when the associated tank (W-9) is in a nonleaking state. It also describes a test conducted on W-9 and the results of that test. In the test, a potassium chloride solution was allowed to drip near the tank to simulate a release. The results show the remarkable sensitivity of the method to even very small "releases" from the tank. The report also describes how the release monitoring plan for Tank W-9 will be implemented while this tank is being used for consolidation purposes. 


\section{INTRODUCTION}

A treatability study and waste removal program are being implemented for the Gunite and Associated Tanks (GAAT) Operable Unit at Oak Ridge National Laboratory (ORNL), Oak Ridge, Tennessee. The treatability study will use Tanks W-3 and W-4 in the North Tank Farm (NTF) to evaluate in-tank sluicing as a means of removing radioactive sludges from the gunite tanks. This method will then be used to remove the sludges from the six tanks in the South Tank Farm (STF). To facilitate the transfer of processed sludges, Tank W-9 in the STF will be used as a temporary consolidation tank. Previous structural and liquid integrity evaluations of W-9 (Lockheed Martin Energy Systems, Inc. 1997) have shown that it is structurally sound and does not leak. Nevertheless, while W-9 is in use as a consolidation tank, it will be instrumented to ensure the detection of potential liquid releases by means of a method that monitors the level of conductivity in the associated dry well. This report documents the instrumentation, the monitoring efforts to establish baseline conductivity conditions, and the simulated liquid release (SLR) testing to demonstrate the effectiveness of conductivity monitoring as a liquid-release detection method for Tank W-9.

The conductivity monitoring method makes use of the existing dry well system adjacent to each of the gunite tanks. These tanks are designed in such a way that any liquid that might be released will collect on the pad beneath the tank and from there drain into the dry well. The conductivity of the liquid in the gunite tanks is very high relative to that of the groundwater in the dry wells $-15,000$ to $30,000 \mu \mathrm{S} / \mathrm{cm}$ as compared with 200 to $500 \mu \mathrm{S} / \mathrm{cm}$. If a release were to occur, the conductivity of the water in the dry well would increase significantly as a result of the contribution from the tank. Monitoring the conductivity of the water in the dry well can thus provide a viable means-and importantly, a means external to the tank - of detecting releases that might occur from the gunite tanks in the NTF and STF.

Monitoring conductivity levels in the dry wells as a release detection method was evaluated as part of the 1995 liquid integrity study (Lockheed Martin Energy Systems, Inc. 1996). The purpose of that study was to develop a method for real-time detection of potential releases during remediation activities that did not rely on tank-internal liquid level measurements. Such a method was desirable because it would allow continuous monitoring of liquid integrity, even while tank operations were underway. In 1996, the conductivity monitoring method was evaluated in more detail, and simulated liquid release demonstrations were conducted on Tanks W-3 and W-4 in the NTF(Vista Research, Inc. 1996). The results of the evaluation indicated that monitoring the conductivity of the water in the dry wells adjacent to the gunite tanks is a very effective method for real-time release detection and should be used as the primary release detection method during the treatability study and waste removal activities. Its application to the tanks in the STF needed to be demonstrated, however, before it could be used reliably as a monitoring tool for Tank W-9.

The dry well conductivity-monitoring method is currently undergoing field evaluation in the STF. There, baseline conductivity monitoring for the dry well adjacent to Tank W-9, as well as SLR testing of W-9 itself, has been completed. The results are provided in this document. Data collection and testing on W-8 and W-10 are still in progress, and those results will be documented in a separate report. Chapter 2 of this report describes the set-up for monitoring conductivity levels and for SLR testing in terms of the location, construction, and instrumentation of Tank W-9 and its dry well, DW-9. Chapter 3 presents the data from the baseline conductivity monitoring in DW-9. Chapter 4 describes 
the SLR test on Tank W-9 and discusses the test results. Chapter 5 describes the plan for monitoring W-9 in its capacity as a consolidation tank; the proposed release detection threshold is also discussed. Conclusions and recommendations are given in Chap. 6, and the references are listed in Chap. 7.

\section{SET-UP FOR CONDUCTIVITY MONITORING AND SLR TESTING IN TANK W-9.}

Tank W-9 is located in the STF, as shown in Fig. 1. Dry well DW-9 is on the northwest side of Tank W-9, as indicated in the figure. A 4-in.-diam polyvinyl chloride(PVC) well screen and riser were inserted into DW-9; a conductivity sensor was then inserted into this protective casing. The conductivity sensor measures the level of conductivity of the groundwater at the bottom of the dry well. For the SLR test, a 1.25-in.-diam steel pipe with a screened drive point was installed at the southeast edge of Tank W-9 on the side of the tank opposite from the dry well (see Fig. 1). The pipe was driven downward from the surface ( $6 \mathrm{ft}$ above the tank) parallel to the vertical wall of the tank and directly adjacent to it. This drain pipe, or "SLR pipe," was the mechanism whereby a solution of water and potassium chloride solution was introduced to simulate a leak from the tank.

Figure 2 shows, in a cut-away view, the relative locations of Tank W-9 and dry well DW-9. This figure is illustrative of tank, pad, and dry well construction in the STF. Because the STF drain system keeps the groundwater level below the bottom of the pad, one can see how a potential release from W-9 would be expected to flow onto the pad and from there into DW-9. The conductivity sensor shown at the bottom of DW-9 was used to collect baseline measurements of groundwater conductivity under ambient conditions and to measure the changes in conductivity produced during the SLR test on Tank W-9.

Proper installation and positioning of the conductivity sensor in DW-9 and of the SLR drain pipe (DP-9) adjacent to the tank was important to the success of the conductivity monitoring and SLR testing on W-9. The PVC well screen that protected the conductivity sensor was installed as close as possible to the inlet pipe in the dry well so as to maximize the sensitivity of the measurements to any higher conductivity liquids that might be flowing from the pad into the dry well. The SLR drain pipe was installed as close to the outside wall of the tank as possible so that the liquid introduced into the pipe during the SLR test would simulate a real release by flowing down the side of the tank and onto the pad.

Before the SLR drain pipe (DP-9) could be installed, the edge of the tank was surveyed, and, with an auger, a test hole was bored from ground level down to the top of the tank; this was to verify the depth between the surface and the tank. A second hole was then bored, adjacent to the first but to a greater depth, to verify that this second hole was on the outer edge of the tank. The steel drive point was then installed at a depth of approximately $6 \mathrm{ft}$ below the top of the tank and as close as possible to its vertical wall. Ten gallons of de-ionized water was poured into DP-9 to test the continuity of the pipe, tank pad, and dry well. The water drained freely out of DP-9. In addition, a decrease in conductivity was observed in the dry well, indicating that the de-ionized water had flowed into it. These results demonstrated that the DP-9 installation was successful.

Figure 2 shows the location ofDP-9, through which the SLR liquid was subsequently poured. The SLR liquid consisted of water to which potassium chloride had been added for the purpose of raising 
conductivity to approximately $15,000 \mu \mathrm{S} / \mathrm{cm}$, which represents the lower end of the range of conductivity for liquids in the gunite tanks of the STF. During the SLR test, this liquid was introduced into DP-9 at a low rate of approximately $0.5 \mathrm{gal} / \mathrm{h}$; the resulting change in conductivity in the dry well, into which the SLR liquid subsequently drained, served as a measure of the viability and sensitivity of the conductivity monitoring method.

A long-handled auger was used to displace the mud-like material at the bottom of DW-9 so that the conductivity sensor could be installed. The auger successfully bored a hole in this material, and the PVC screen and riser were installed directly in front of the orifice of the inlet pipe leading from the tank pad. The conductivity sensor was then placed into the PVC casing and lowered to the bottom of the dry well. The location of each of these components is shown in Fig. 3. The water level in DW-9, as shown in this figure, reaches just to the bottom of the inlet pipe.

The results of the baseline conductivity monitoring in dry well DW-9, conducted before the SLR test on Tank W-9, are presented in Chap. 3. The SLR testing on Tank W-9 and the results are presented in Chap. 4.

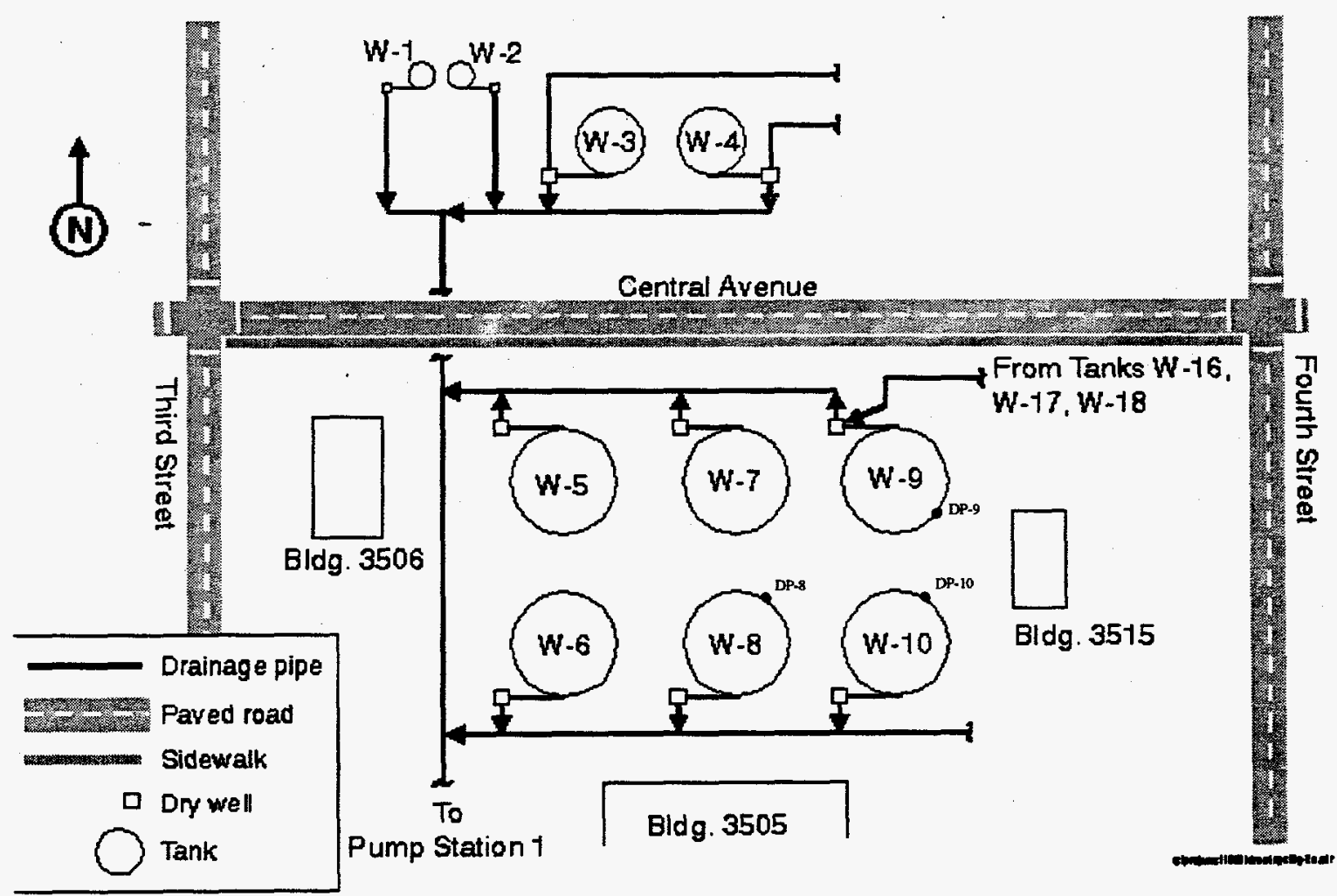

Fig. 1. Plan view of NTF and STF showing the location of the GAAT, including Tank W-9, the dry wells, and the SLR drain pipe DP-9. 


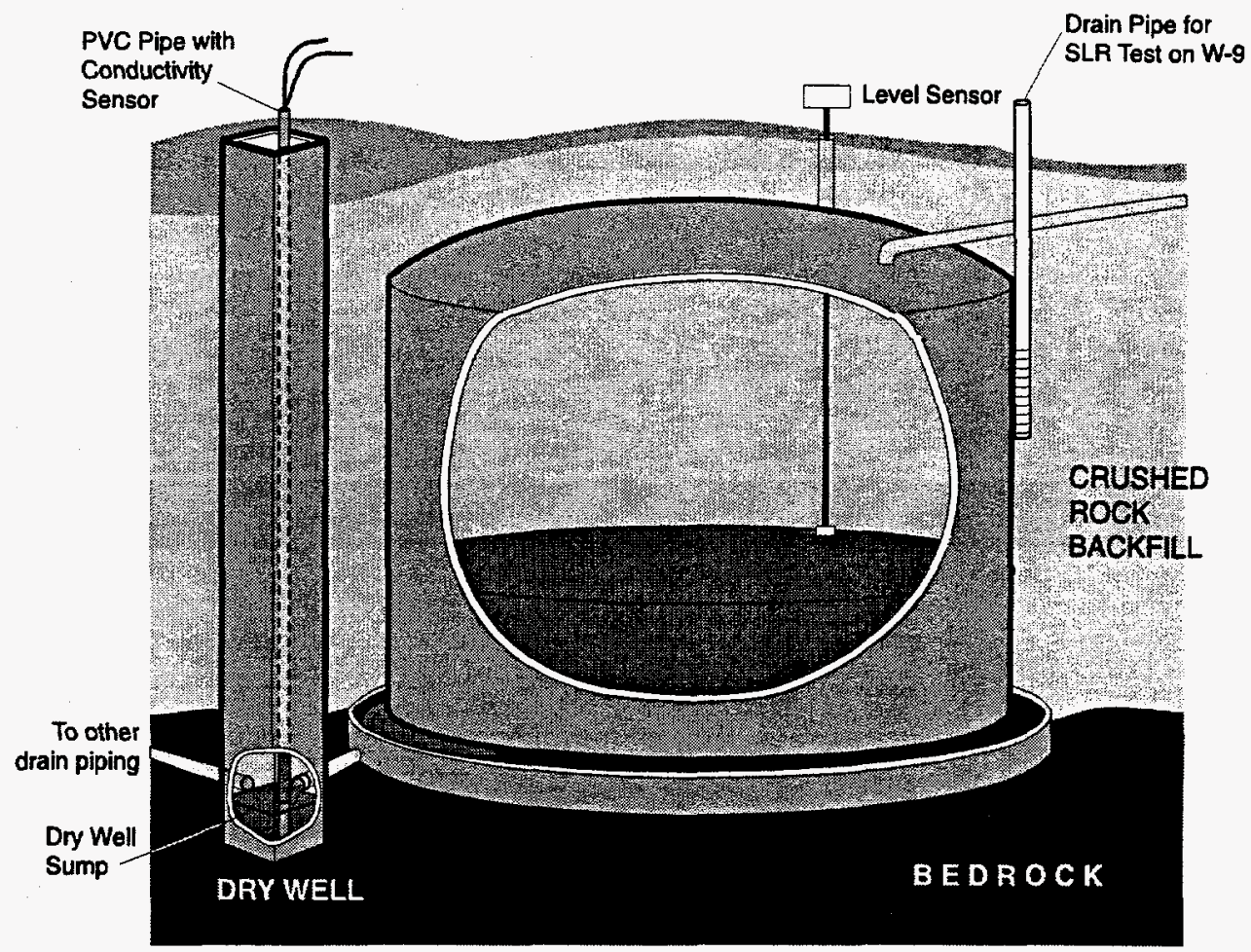

Fig. 2. Cut-away view of Tank W-9 showing the tank, tank pad, dry well, and drain pipe for the SLR test.

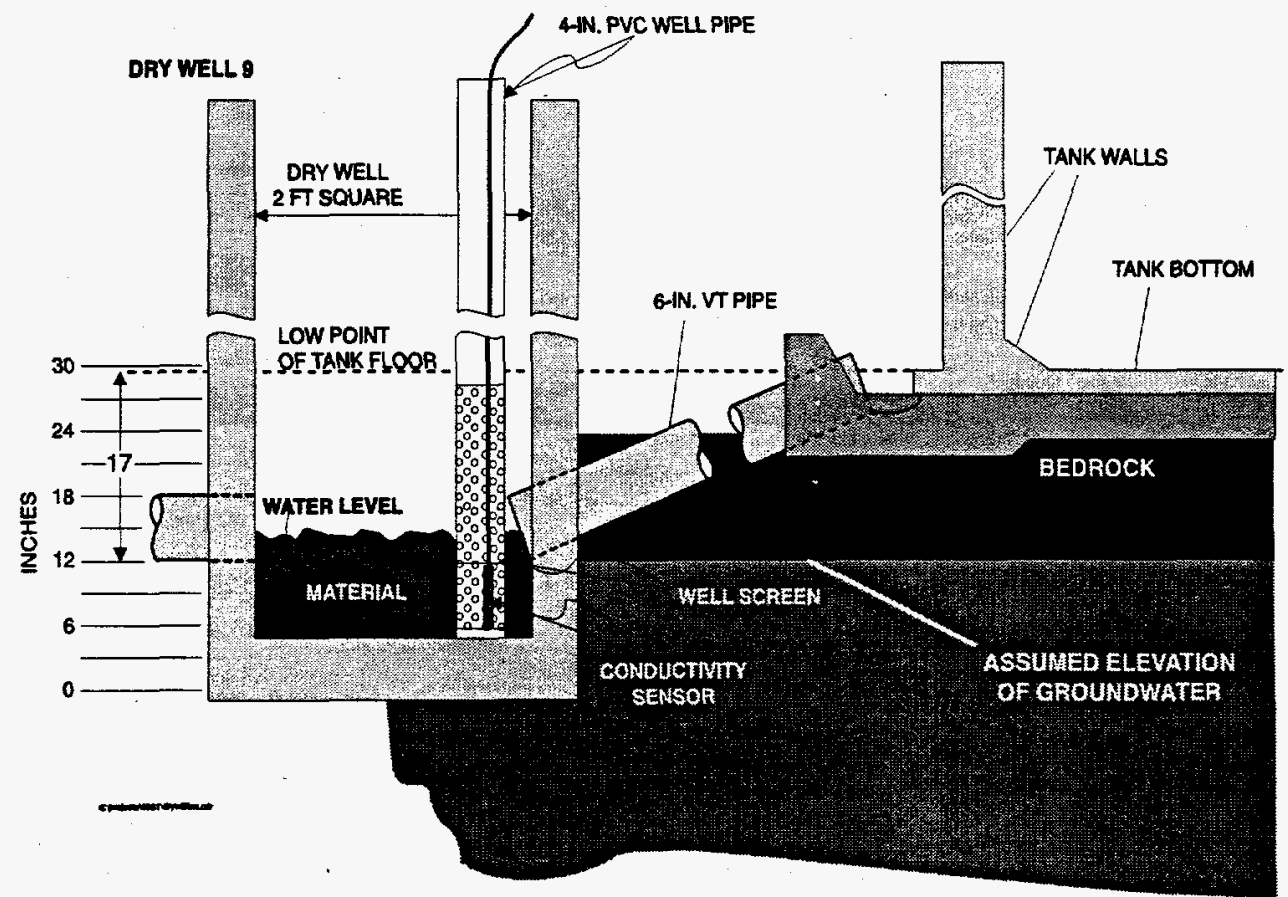

Fig. 3. Cross section of DW-9 showing the location of the PVC screen and riser, the conductivity sensor, and the level of water in the dry well. 


\section{RESULTS OF BASELINE CONDUCTIVITY MONITORING IN DRY WELL DW-9}

The instrumentation and baseline conductivity monitoring data for dry well DW-9 is presented in this chapter. The purpose of the baseline conductivity monitoring was to establish the normal range and statistics for conductivity measurements of the groundwater in the bottom of DW-9. This information was then compared with the changes in conductivity observed during the subsequent SLR test on tank W-9.

The conductivity measurements were made using a Great Lakes Instruments small-bore, electrodeless conductivity sensor (Model 3625E27). The sensor was calibrated before installation by the ORNL Instrumentation and Controls Division and set up with a range of 0 to $4000 \mu \mathrm{S} / \mathrm{cm}$. As discussed in Chap. 2, the sensor is submerged below the level of the groundwater at the bottom of the dry well and is located inside a well screen that keeps it free of sediment and other material. The sensor is controlled at the surface by a transmitter. This allows the sensor to be powered by a $4-$ to $20-\mathrm{mA}$ instrument circuit. The surface transmitter also allows the sensor to be periodically field calibrated. Measurements made by the sensor are sampled and recorded every $30 \mathrm{~min}$ with a portable, batterypowered logger.

The baseline monitoring data for DW-9 were collected from May 15 through June 16, 1997. The data were downloaded from the logger weekly. The data files were processed and reviewed by Vista Research, Inc., and assembled into a single baseline data file. A plot of the baseline conductivity data for DW-9 is shown in Fig. 4. The data are plotted in $\mu \mathrm{S} / \mathrm{cm}$ versus time. Cumulative rainfall data in inches for the period indicated is also plotted. As can be seen in Fig. 4, the conductivity of the groundwater in DW-9 ranged between 216 and $374 \mu \mathrm{S} / \mathrm{cm}$, with a mean value of $311 \mu \mathrm{S} / \mathrm{cm}$ and a standard deviation of $30 \mu \mathrm{S} / \mathrm{cm}$. The typical range for ground water in noncontaminated areas is from 200 to $500 \mu \mathrm{S} / \mathrm{cm}$. Small changes (decreases) in conductivity corresponding to rainfall events (seen

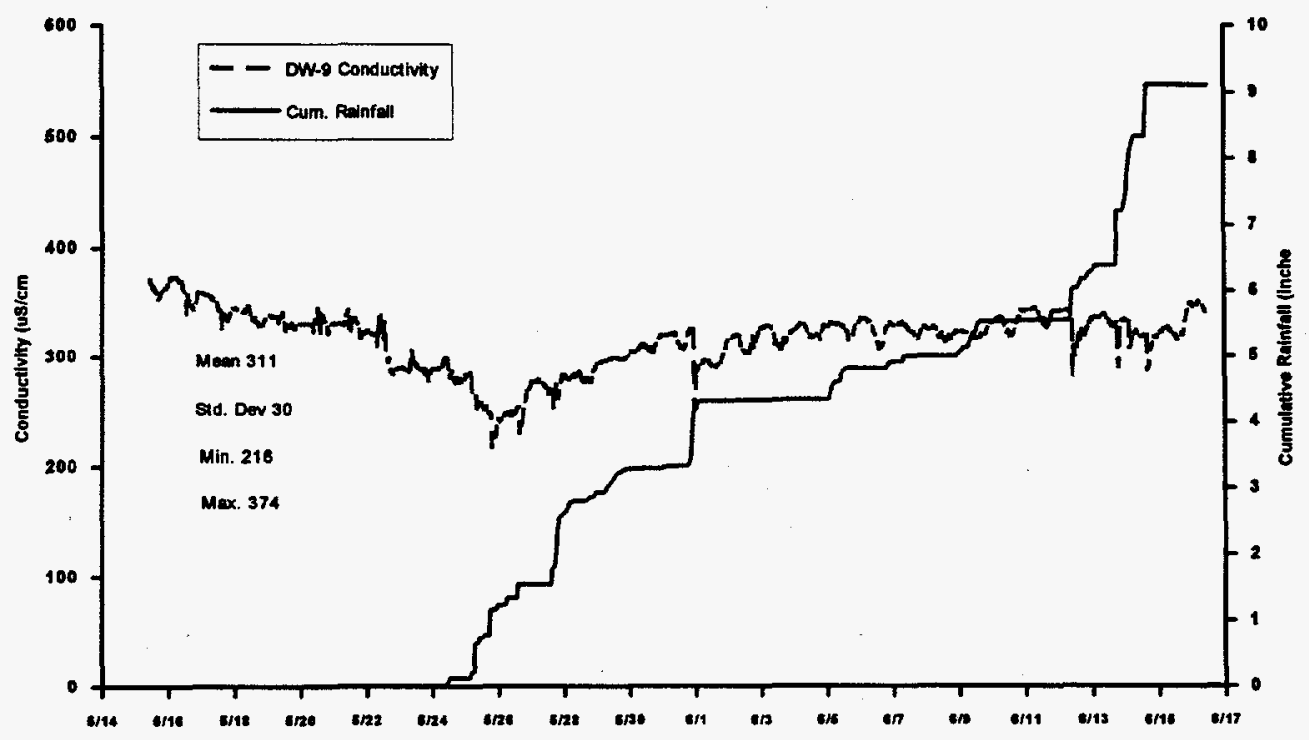

Fig. 4. Plot of DW-9 conductivity and ORNL cumulative rainfall data from May 15 through June 16, 1997. 
as jumps or increases in cumulative rainfall) can be seen in the data. Overall, the measured conductivity levels remained fairly constant during the baseline monitoring. On the basis of these data and the assumption that the conductivity method provides information regarding the liquid integrity of the tank (as will be shown later), the earlier findings (Lockheed Martin Energy Systems, Inc. 1997) that Tank W-9 is tight and leak free are confirmed.

On the basis of these data, a change in conductivity that was three standard deviations $(90+\mu \mathrm{S} / \mathrm{cm})$ above the maximum measured value of $374 \mu \mathrm{S} / \mathrm{cm}(\approx 475 \mu \mathrm{S} / \mathrm{cm})$ in DW-9 would be indicative of higher conductivity water getting into the dry well. If the conductivity were to increase significantly above the 475 value, a potential liquid release from Tank W-9 would be indicated. The results of the SLR tests show that even a very small simulated release causes the conductivity in DW-9 to increase significantly above the baseline measurements and the 475 value.

\section{RESULTS OF SLR TEST ON TANK W-9}

An SLR test was conducted on Tank W-9 from 12:30 p.m. on June 16, 1997, through 8:30 a.m. on June 20, 1997, a period of 92 hours. In this test, potassium chloride was mixed with water in a 55gal drum in sufficient concentration to achieve a solution conductivity of about $15,000 \mu \mathrm{S} / \mathrm{cm}$. This value, which was selected because it is conservative, is at the low end of the range of conductivity of the liquids in the gunite tank; this range has been measured at $15,000 \mu \mathrm{S} / \mathrm{cm}$ to over $30,000 \mu \mathrm{S} / \mathrm{cm}$ (Lockheed Martin Energy Systems, Inc. 1997). A peristaltic pump was used to meter the flow of the SLR liquid from the drum into the SLR drain pipe adjacent to Tank W-9, as described in Chap. 2. For the entire SLR test, the flow rate from the pump was calibrated and set to $0.5 \mathrm{gal} / \mathrm{h}$. This value was checked several times during the test by using a graduated cylinder and a stop watch.

The conductivity measurements in DW-9 were recorded by the data logger every $30 \mathrm{~min}$. Manual readings were also taken from the data logger before the test and again a few hours after the test began. Within $3 \mathrm{~h}$ of the start of the SLR test (i.e., $3 \mathrm{~h}$ after the SLR liquid started draining down DP-9), the conductivity in DW-9 began to increase. Figure 5 is a plot of the DW-9 conductivity data, covering a period beginning about 3 days before the start of the SLR test and ending about 10 days after it. (Also shown is the cumulative rainfall data from the ORNL meteorological tower.) The increase in conductivity that resulted from the introduction of the SLR liquid into DP-9 is dramatic and can easily be seen on the plot. Within a day, conductivity increased from approximately $370 \mu \mathrm{S} / \mathrm{cm}$ to more than $800 \mu \mathrm{S} / \mathrm{cm}$. During the $92-\mathrm{h}$ test, conductivity increased to more than $1500 \mu \mathrm{S} / \mathrm{cm}$.

The response in DW-9 to the $0.5-\mathrm{gal} / \mathrm{h}$ simulated release clearly demonstrates that monitoring the conductivity of the water in the dry well is an effective and sensitive method of release detection. Because the baseline conductivity of the groundwater has an average value that remains close to $311 \mu \mathrm{S} / \mathrm{cm}$, and because it increased to more than $1500 \mu \mathrm{S} / \mathrm{cm}$ with a simulated leak of just $0.5 \mathrm{gal} / \mathrm{h}$, these results also confirm the results of the prior analysis of the internal-level data-that Tank W-9 is not currently leaking. Because DP-9 was installed diametrically opposite DW-9 (see Fig. 1), these results also demonstrate that the concrete pad underlying W-9 is integral, free of cracks and fissures, and that any liquid released from W-9 will drain into DW-9.

The cumulative rainfall data in Fig. 5 shows some interesting effects. Before the SLR test, several inches of rain fell over the course of a couple of days. This caused a few blips in the baseline data but did not change it significantly. It indicates that, when rainwater infiltrates a dry well containing 
groundwater, the resulting mix is slightly lower in conductivity. About $0.5 \mathrm{in}$. of rain fell on June 17 , during the SLR test. Although a slight blip can be seen in the conductivity data as a result of infiltration of rainwater, conductivity levels continued to increase after the rainfall event. Several days after the SLR test had ended, another 0.5 in. of rain was recorded (on June 22). This event caused the concentration in DW-9 to decrease from $1500 \mu \mathrm{S} / \mathrm{cm}$ down to around $800 \mu \mathrm{S} / \mathrm{cm}$. The conductivity of the water in the dry well then decreased slowly over the next week. Another rainfall event on June 30 reduced the concentration further to within the normal baseline range. These data indicate that groundwater and infiltrating rainwater slowly flow through the dry well and that the baseline measurements made in DW-9 are representative of the normal concentrations of groundwater and infiltrating rainwater. They also show that even very small simulated leaks can be easily detected above the normal flushing action of the groundwater and the infiltration of rainwater.

The baseline conductivity monitoring effort and the results of the SLR test provide sufficient data to establish a preliminary release detection threshold for Tank W-9. As noted in Chap. 3, a conductivity value of about $475 \mu \mathrm{S} / \mathrm{cm}$ is approximately three standard deviations above the maximum value recorded in DW-9 during the baseline study there. If the conductivity in DW-9 exceeds this value, then there is at least a $99 \%$ chance that the change is more than just random error. That is, should such a change occur, the tank may be leaking. Although a value of about 475 to $500 \mu \mathrm{S} / \mathrm{cm}$ might be used as a release detection threshold, it might also be too low and thus lead to a high incidence of false alarms. This is because the conductivity of the groundwater in DW-9 has not been studied year-round, and this dry well might experience larger fluctuations during other parts of the year. To prevent false alarms from interfering needlessly with the treatability study and waste removal program and yet retain the sensitivity to detect small leaks, a preliminary threshold of $900 \mu \mathrm{S} / \mathrm{cm}$ has been selected. Until further baseline data is collected and analyzed, this value represents a reasonable compromise between achieving a high probability of detecting a small release (a few tenths of a gallon per hour) and maintaining a low probability of false alarm. As more data are collected and a more confident estimate of the statistics of the DW-9 conductivity values is developed, the threshold value can be changed, if that is indicated.

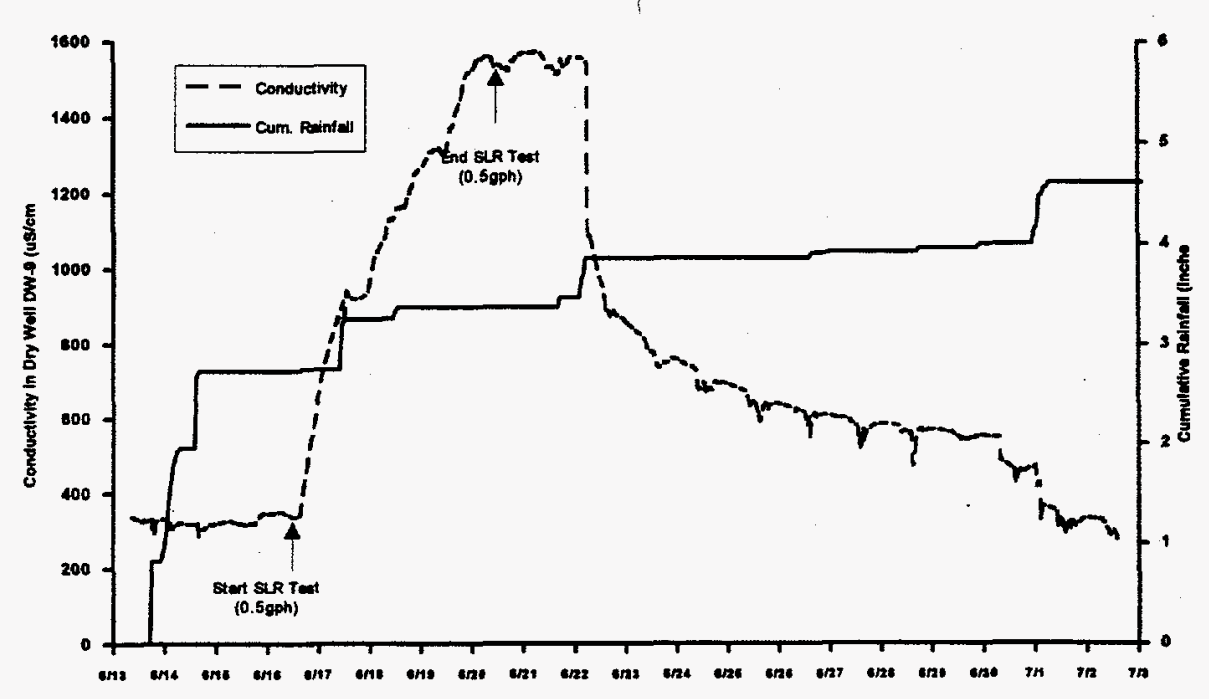

Fig. 5. Plot of SLR test on Tank W-9 (12:30 p.m. on June 16 through 8:30 a.m. on June 20,1997) before, during, and after the SLR test period, showing conductivity data from DW-9 and cumulative rainfall data (June 13 to July 2, 1997). 


\section{MONITORING PLAN FOR W-9 CONSOLIDATION TANK}

The instrumentation in DW-9 will continue to be used to collect additional baseline conductivity data and to conduct the monitoring operations for Tank W-9 in its role as a consolidation tank. Measuring the conductivity of the groundwater in DW-9 will be the primary means for release detection and for monitoring tank integrity. Therefore, during the operational phase, the monitoring sensors will be connected to the Waste Operations Control Center or to the waste removal equipment control center. The system will be set up to provide the operators with real-time data and conductivity threshold alarms. The preliminary alarm threshold for Tank W-9 will be a conductivity level of 900 $\mu \mathrm{S} / \mathrm{cm}$ in the dry well DW-9. Procedures will be prepared for the operators specific to the conductivity monitoring sensor for consolidation Tank W-9. The data will continue to be logged to document operating conditions and provide additional supporting data for baseline conditions and alarms. The data will be compiled and summarized monthly and periodic reports will be prepared to document the monitoring results for the W-9 consolidation tank.

The conductivity sensor in DW-9 was calibrated by the ORNL Instrumentation and Controls Division before installation. The sensor will be field calibrated at least every 2 months and just before the initial use of Tank W-9 for waste consolidation. The transmitter that controls the sensor has shown some sensitivity to moisture and heat. Routine maintenance checks will be performed to keep the transmitter dry while it is connected to either the data logger or the real-time monitoring system. Steps have been taken to keep it shaded and out of the direct sunlight.

\section{CONCLUSIONS AND RECOMMENDATIONS}

The work reported here makes several important points regarding the conductivity method, the integrity of the W-9 system, and the utility of the method as it is applied to the GAAT treatability study and waste removal program. First, the body of the work shows that the method is a viable tool for monitoring the integrity of the GAAT as they are being remediated. Further, unlike internal monitoring schemes, the conductivity method works well even while in-tank operations are ongoing. Second, the monitoring program is economical and requires no new instrumentation to be added to the tanks that could interfere with the remediation of those tanks. The probes that are installed are external to the tank, easy to service, and relatively inexpensive. Third, a preliminary release-detection threshold has been established for W-9 that will allow reliable detection of small leaks with a low probability of false alarm. And lastly, the monitoring program that has been implemented around the conductivity method is a $24-\mathrm{h} /$ day program that is simple and intuitive and requires little operator training.

Regarding the W-9 tank system itself, the results of the work reported here validate and underscore the liquid integrity assessment made earlier, which used the changes in level over time as the sensed quantity. Simply put, W-9 is not leaking; the baseline and SLR data quite conclusively show this. Further, because DP-9 was located diametrically opposite DW-9, the SLR test results show that the concrete pad beneath Tank W-9 is not cracked or fissured in any way that would prevent a release from W-9 from being detected. And finally, the results show that the STF drain system is working very well, at least insofar as it applies to W-9. This is an important result because the NTF SLR tests performed earlier showed that the NTF-to-Pump Station 1 drain was working and retaining all of the SLR liquid pumped into test pipes DP-3 and DP-4. 
Taken together, all this means that W-9 is not presently leaking, and anything that might be released from W-9 in the future will be quickly detected so that appropriate response action can be taken.

\section{REFERENCES}

Lockheed Martin Energy Systems, Inc. 1997. Evaluation and Monitoring Plan for Consolidation Tanks: Gunite and Associated Tanks Operable Unit, Waste Area Grouping 1, Oak Ridge National Laboratory, Oak Ridge, Tennessee, ORNL/ER-396, Lockheed Martin Energy Systems, Inc., Oak Ridge, Tenn.

Lockheed Martin Energy Systems, Inc. 1996. Preliminary Evaluation of Liquid Integrity Monitoring Methods for Gunite and Associated Tanks at the Oak Ridge National Laboratory, ORNL/ER349, Lockheed Martin Energy Systems, Inc., Oak Ridge, Tenn.

Vista Research, Inc. 1996. Simulated Liquid Release Demonstrations on Gunite Tanks $W-3$ and W-4 in the North Tank Farm, Vista Research Report 1060-TR-96-001, Vista Research, Inc., Oak Ridge, Tenn. 


\section{DISTRIBUTION}

1. L. V. Asplund

2. O. W. Hale

3. L. Holder, Jr.

4. M. A. Johnson

5. T. M. Koepp

6. P. T. Owen

7. L. B. Raulston

8. A. D. Reynolds

9. S. D. Van Hoesen

10. Central Research Library

11. File-EMEF DMC-RC

12. J. G. Morse, Vista Research, Inc., 101 N. Rutgers Ave., Oak Ridge, TN 37830 